\title{
Laboratory Study on the Potential EOR Use of HPAM/VES Hybrid in High-Temperature and High-Salinity Oil Reservoirs
}

\author{
Dingwei Zhu, ${ }^{1,2}$ Jichao Zhang, ${ }^{3}$ Yugui Han, ${ }^{3}$ Hongyan Wang, ${ }^{3}$ and Yujun Feng ${ }^{1,3,4}$ \\ ${ }^{1}$ Chengdu Institute of Organic Chemistry, Chinese Academy of Sciences, Chengdu 610041, China \\ ${ }^{2}$ University of Chinese Academy of Sciences, Beijing 100039, China \\ ${ }^{3}$ EOR Laboratory, Geological Scientific Research Institute, Shengli Oilfield Company of SINOPEC, Dongying 257013, China \\ ${ }^{4}$ State Key Laboratory of Polymer Materials Engineering, Polymer Research Institute, Sichuan University, Chengdu 610065, China
}

Correspondence should be addressed to Yujun Feng; yjfeng@cioc.ac.cn

Received 6 April 2013; Revised 12 July 2013; Accepted 12 July 2013

Academic Editor: Ibnelwaleed Ali Hussien

Copyright (C) 2013 Dingwei Zhu et al. This is an open access article distributed under the Creative Commons Attribution License, which permits unrestricted use, distribution, and reproduction in any medium, provided the original work is properly cited.

\begin{abstract}
Polymer flooding represents one of the most efficient processes to enhance oil recovery, and partially hydrolyzed polyacrylamide (HPAM) is a widely used oil-displacement agent, but its poor thermal stability, salt tolerance, and mechanical degradation impeded its use in high-temperature and high-salinity oil reservoirs. In this work, a novel viscoelastic surfactant, erucyl dimethyl amidobetaine (EDAB), with improved thermal stability and salinity tolerance, was complexed with HPAM to overcome the deficiencies of HPAM. The HPAM/EDAB hybrid samples were studied in comparison with HPAM and EDAB in synthetic brine regarding their rheological behaviors and core flooding experiments under simulated high-temperature and high-salinity oil reservoir conditions $\left(T: 85^{\circ} \mathrm{C}\right.$; total dissolved solids: $\left.32,868 \mathrm{mg} / \mathrm{L} ;\left[\mathrm{Ca}^{2+}\right]+\left[\mathrm{Mg}^{2+}\right]: 873 \mathrm{mg} / \mathrm{L}\right)$. It was found that the HPAM/EDAB hybrids exhibited much better heat- and salinity-tolerance and long-term thermal stability than HPAM. Core flooding tests showed that the oil recovery factors of HPAM/EDAB hybrids are between those of HPAM and EDAB. These results are attributed to the synergistic effect between HPAM and EDAB in the hybrid.
\end{abstract}

\section{Introduction}

Among all the chemically enhanced oil recovery (CEOR) processes, polymer flooding represents one of the most efficient methods to produce residual oil from depleted and water-flooded reservoirs $[1,2]$. In this process, the increased viscosity of the displacing fluid by the added water-soluble polymer will improve the mobility ratio between the injected fluid and the reservoir oil, mobilizing the capillary trapped water-flooded oil in the secondary stage, leading to better vertical and areal sweep efficiencies and thus higher oil recovery efficiencies [2]. In China, around 13 million tons of oil is produced additionally per year by this chemical flooding technique.

Partially hydrolyzed polyacrylamide (HPAM) is the most widely used oil displacement agent and has been successfully employed in polymer flooding worldwide [2-4]. As an anionic polyelectrolyte, HPAM is easily to be dissolved in water and shows strong thickening ability in fresh water at relatively lower dosage. Nevertheless, the notorious congenital drawbacks of HPAM also limit its applications in hostile environment, in particular, the high-temperature, high-salinity, and low-permeability oil reservoirs [5], such as the Class III reserve of Shengli Oil Field in China where the temperature is above $85^{\circ} \mathrm{C}$ and the salinity (total dissolved solids, TDS) is higher than $30,000 \mathrm{mg} / \mathrm{L}$ in which the total amount of $\mathrm{Ca}^{2+}$ and $\mathrm{Mg}^{2+}$ exceeds $800 \mathrm{mg} / \mathrm{L}$. In such a harsh environment, the interaction of metal ions in the oil field brines largely shields the mutual repulsion from the carboxylic groups along the HPAM skeleton, leading the polymer coils to collapse, decreasing hydrodynamic volume, and thus ultimately lowering solution viscosity [2]. Efficiency loss of HPAM aqueous solution at elevated temperature becomes further serious as more amide groups undergo extensive hydrolysis into carboxylic characters, and the resulting hydrolyzed products precipitated when contacting $\mathrm{Ca}^{2+}$ and $\mathrm{Mg}^{2+}$ [6], commonly present in oil reservoir brines or hard water. 
Another major limitation of HPAM is its flow-induced mechanical degradation. As a synthetic polymer, HPAM is intrinsically linear, flexible, high-molecular weight (generally higher than ten million), and highly polydispersible in molecular weight (polydispersity index normally between 2 and 3). When it is mixed and dissolved in tanks, or it is passing through chokes, pipes, valves, nozzles, pumps, perforations near wellbore, or the pore throat in the porous media, HPAM chains are subjected to both shear flows and elongation flows [7]. In pure shear flows where the shear rate is perpendicular to the flow direction, HPAM molecules rotate and are thus subjected to periodic extensional and compressional stresses. As shear rate increases, hydrodynamic stresses increase and their effects are nonnegligible compared with those of Brownian motion when rotation time becomes smaller than the longest rotational relaxation time. In pure elongational flows where the elongation rate is parallel to flow direction, the effective deformation that occurs in the flow direction may be very large for the flexible HPAM and a full stretching is achieved only if the macromolecule remains in the elongational flow over a sufficiently long time. When submitted to shear, macromolecules do not stretch significantly, whereas when submitted to extension, they can elongate drastically and break. The first consequence of macromolecule stretching in elongational flows is a strong increase in viscosity. For high-molecular-weight HPAM used in EOR, the elongational viscosity may be as high as $10^{4}$ times the zero-shear-rate viscosity. The second consequence is that the macromolecule is subjected to an internal tensile. It has been shown that elongation force could possibly be high enough to exceed the carbon-carbon bond force and thus may cause chain breakage, that is, mechanical degradation of HPAM chains [7]. This degradation process essentially breaks the larger molecules up into smaller fragments and thus changes the molecular weight distribution of the HPAM, which hinders the efficiency of the EOR technique $[8,9]$.

Facing these severe challenges, two options were naturally used to improve the properties of HPAM in high-temperature and high-salinity environment; one is introducing thermostable and more salt-tolerant monomer or groups such as $\mathrm{SO}_{3}{ }^{-}$onto the HPAM backbone [10], and the second is increasing molecular weight of HPAM (maximum $35 \times$ $10^{6} \mathrm{~g} / \mathrm{mol}$ to date) to get higher viscosity retention. However, the main portion in the first case is still the acrylamide segment which shows poor long-term thermal stability and salt tolerance, and in the second case, the increased molecular weight of HPAM will bring about easier mechanical degradation [7] and the plugging of the smaller pore throat in the low-permeability oil reservoirs. Thus, we shifted our attention to seek other alternatives with better salt tolerance and thermal stability, as well as improved mechnical stability, and we found recently that viscoelastic surfactant (VES) is one of such choices amongst others.

Viscoelastic surfactants are formed from the entanglement of worm-like micelles (WLMs) by certain surfactants in the presence of an organic or inorganic hydrotrope [11]. WLMs are long flexible aggregates of surfactant molecules in aqueous solution, and above a surfactant concentration threshold, WLMs entangle into a transient network that is constantly breaking and reforming, for which they are also referred to as "living" or "equilibrium" polymers $[12,13]$. The entanglement of WLMs imparts strong thickening ability of water and remarkable viscoelastic properties to the solution. These peculiar rheological properties of VES, including reversible breaking and formation, viscoelastic response analogous to polymer solutions, and strong viscosifying ability, may furnish them to be applied in CEOR process.

Up to date, most of the VES systems are composed of cationic surfactants whose hydrophobic tail is normally shorter than C18. The strong adsorption between these cationic amphiphiles and negatively charged sandstone, as well as high dosage needed to thicken injection fluid, impeded their practical use in EOR process. To overcome these deficiencies of cationic VES, we recently developed ultra-long chain particularly C22-tailed zwitterionic [14-19], anionic [20,21], nonionic [22] surfactants which are capable of forming WLMs at much lower concentration; that is, the overlapping concentration $\left(C^{*}\right)$ is much lower than those of $\mathrm{C} 16$ cationic counterparts. Apart from these advantages, the C22-tailed zwitterionic surfactants-3-(nerucamidopropyl$\mathrm{N}, \mathrm{N}$-dimethyl ammonium) propane sulfonate (EDAS) [1417, 19] also show additional advantages such as insensitivity to inorganic salt, sufficient stability over the whole $\mathrm{pH}$ range [14], and long-term thermal stability [15]. These unique properties of EDAS make it suitable for potential use in high-temperature and high-salinity reservoirs. Nevertheless, the betaine agent to prepare EDAS, 1,3-propanesultone, is extremely poisonous and carcinogenic, restricting the scaleup production and industrial use of EDAS in tertiary oil recovery.

Thus, in this work, a newly synthesized carboxylate counterpart of EDAS, erucyl dimethyl amidopropyl betaine (EDAB), was chosen for the study of its possible use in chemical EOR process. Compared with its saturated-chain counterparts, EDAB shows improved water solubility and much lower critical micelle concentration [18]. However, we found that the oil recovery factor from single VES solution is quite low. Therefore, HPAM was used to complex with EDAB to form hybrids which were systematically examined to see their potential in CEOR process. Reported here are the rheological behaviors and preliminary core flooding results of these hybrids under simulated high-temperature and high-salinity oil reservoirs of Shengli oil Field. For comparison, HPAM and EDAB were also tested under the same experimental conditions.

\section{Experimental}

2.1. Materials. HPAM (Scheme 1) with viscosity-averaged molecular weight of $1.2 \times 10^{7} \mathrm{~g} / \mathrm{mol}$ was obtained from Beijing Hengju Chemical Group Co., Ltd. The hydrolysis degree and active content of this polymer are $24 \%$ and $89.9 \%$, respectively. EDAB (Scheme 1) was prepared by the reaction of the corresponding fatty acids with $N, N$-dime-thyl-1,3propanediamine, followed by quaternization with sodium chloroacetate of the obtained intermediates [18]. All other 


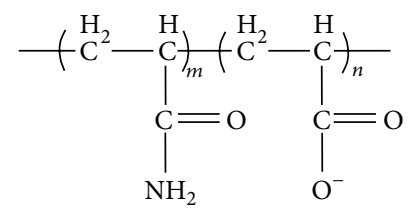

HPAM

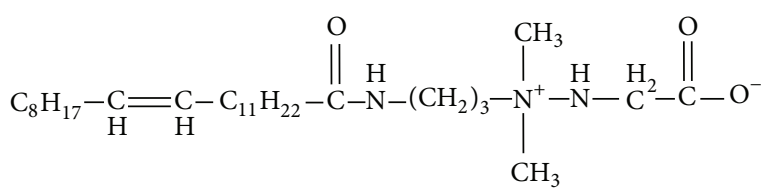

EDAB

Scheme 1: Molecular structures of HPAM and EDAB used in this work.

TABLE 1: The nomenclature and compositions of chemicals used in this work.

\begin{tabular}{lcc}
\hline Sample name & HPAM (wt\%) & EDAB (wt\%) \\
\hline P30 & 0.3 & 0 \\
E30 & 0 & 0.3 \\
P25E5 & 0.25 & 0.05 \\
P20E10 & 0.20 & 0.10 \\
P15E15 & 0.15 & 0.15 \\
P5E25 & 0.05 & 0.25 \\
\hline
\end{tabular}

chemicals used are analytical grade, and the water used is doubly distilled.

2.2. Preparation of Hybrid Samples. The HPAM or EDAB stock solutions with concentration of $0.3 \%$ were separately prepared by dissolving designed amount of powders into synthetic brine (TDS: $32,868 \mathrm{mg} / \mathrm{L} ;\left[\mathrm{Ca}^{2+}\right]+\left[\mathrm{Mg}^{2+}\right]: 873 \mathrm{mg} / \mathrm{L}$ ) with gentle stirring at room temperature. The TDS and hardness of the brine are close to those of connate water in the Reserve III of Shengli Oil Field. The hybrid samples were prepared by mixing EDAB solution with HPAM solution following the designed recipe and gently stirred for 3 days, and then left to stand for 1 day prior to test. The sample code "PxEy" refers to the concentration of the two chemicals in the mixture (Table 1).

2.3. Rheology Test. All rheological measurements were carried out on a Physica MCR301 (Anto-Paar, Austria) rotational rheometer equipped with concentric cylinder geometry CC27. The radii of the measuring bob and the measuring cup are 13.33 and $14.46 \mathrm{~mm}$, respectively. The temperature was controlled by a Peltier system that provides fast and precise adjustment of the temperature during heating. A solvent trap was used to prevent evaporation of the solvents during measurement.

The apparent viscosity $\left(\eta_{\text {app }}\right)$ of the samples was measured at $85^{\circ} \mathrm{C}$ with a fixed shear rate $(\dot{\gamma})$ of $7.34 \mathrm{~s}^{-1}$. Steady shear viscosity was recorded during temperature scans going from
20 to $85^{\circ} \mathrm{C}$ (heating rate $=2^{\circ} \mathrm{C} / \mathrm{min}$ ). The elastic and storage moduli of the samples were registered during the angular frequency scans from 0.05 to $100 \mathrm{rad} \cdot \mathrm{s}^{-1}$ at $85^{\circ} \mathrm{C}$ with the same rheometer.

2.4. Long-Term Thermal Stability Test. $0.05 \% \mathrm{Na}_{2} \mathrm{~S}_{2} \mathrm{O}_{3}$ is added into all the samples as an oxygen scavenger, and the sample solutions were distributed into $120-\mathrm{mL}$ glass bottles, and then sealed with a cover, followed by placing them into an oven and aged at $85^{\circ} \mathrm{C}$. At consecutive time intervals, the samples were taken out for viscosity monitoring.

2.5. Core Flooding Test. The core flooding tests were performed under the simulated high-temperature and highsalinity oil reservoirs in Shengli Oil Field of China and followed a previously reported procedure [23]. A steel cylinder with $2.5 \mathrm{~cm}$ in inner diameter and $25 \mathrm{~cm}$ in height was packed with several sizes of silica sand in model. The porosity of sandstone core was $32.6 \%$. The sand pack was initially saturated with the synthetic brine, followed by injecting the dehydrated Shengli oil to $\sim 70 \%$. The density of dehydrated Shengli oil was $0.95 \mathrm{~g} / \mathrm{cm}^{3}$ and the viscosity was $40.1 \mathrm{mPa} \cdot \mathrm{s}$. The core was then injected with the synthetic brine until the water content was higher than $98 \%$ in the output fluid, and the injection of $30 \%$ pore volume (PV) of the sample solution was followed. The total oil recovery and the oil recovery by water flooding were calculated, respectively, and the difference between them was the tertiary oil recovery factor by polymer or polymer/surfactant hybrid flooding. The injection rate of the sample was maintained at $0.23 \mathrm{~mL} / \mathrm{min}$, and the cylindrical sand pack was placed in a chamber and heated at $85^{\circ} \mathrm{C}$ throughout the test.

\section{Results and Discussion}

3.1. Rheological Behaviors of HPAM/EDAB Hybrid Samples. It is well accepted that apparent viscosity of polymer solution plays a crucial role in displacing less viscous oil in the EOR process [24]. Therefore, it is necessary to investigate the viscous properties of the hybrid samples before flooding test.

Exhibited in Figure 1 are the apparent viscosities of different samples plotted against temperature. As expected, $\eta_{\text {app }}$ of HPAM solution (P30) decreases continuously upon increasing temperature, with a general trend following Arrhenius laws. The final $\eta_{\text {app }}$ at $85^{\circ} \mathrm{C}$ is just one-third of the original value at room temperature, which implies that the HPAM solution shows pure thermothinning behavior. However, $\eta_{\text {app }}$ of EDAB solution (E30) decreases sharply before $25^{\circ} \mathrm{C}$, following an unstable increase until $56^{\circ} \mathrm{C}$, after which the viscosity drops again. Typically, its viscosity between 70 and $85^{\circ} \mathrm{C}$ remains unchanged. But if one compares the $\eta_{\text {app }}$ of $\mathrm{EDAB}$ at 30 and $85^{\circ} \mathrm{C}$, you will find that there is no change between them. This means that EDAB is less thermosensitive than HPAM. Interestingly, the HPAM/EDAB hybrid samples such as P15E15 and P10E20 exhibit more similar behavior to EDAB rather than HPAM solution. Both of the two hybrid samples show inverted "V" shape in viscosity-temperature curves, all of which have a viscosity peak $55^{\circ} \mathrm{C}$, analogous 
TABLE 2: Apparent viscosity of the samples measured at simulated high-temperature and high-salinity oil reservoirs (TDS $=32,868 \mathrm{mg} / \mathrm{L}$, $\left.\left[\mathrm{Ca}^{2+}\right]+\left[\mathrm{Mg}^{2+}\right]=873 \mathrm{mg} / \mathrm{L}, \mathrm{T}=85^{\circ} \mathrm{C}, \dot{\gamma}=7.34 \mathrm{~s}^{-1}\right)$.

\begin{tabular}{lccccccc}
\hline Sample & P30 & P25E5 & P20E10 & P15E15 & P10E20 & P5E25 & E30 \\
\hline$\eta_{\text {app }}(\mathrm{mPa} \cdot \mathrm{s})$ & 17.93 & 11.34 & 8.59 & 11.25 & 30.61 & 18.29 & 28.04 \\
\hline
\end{tabular}

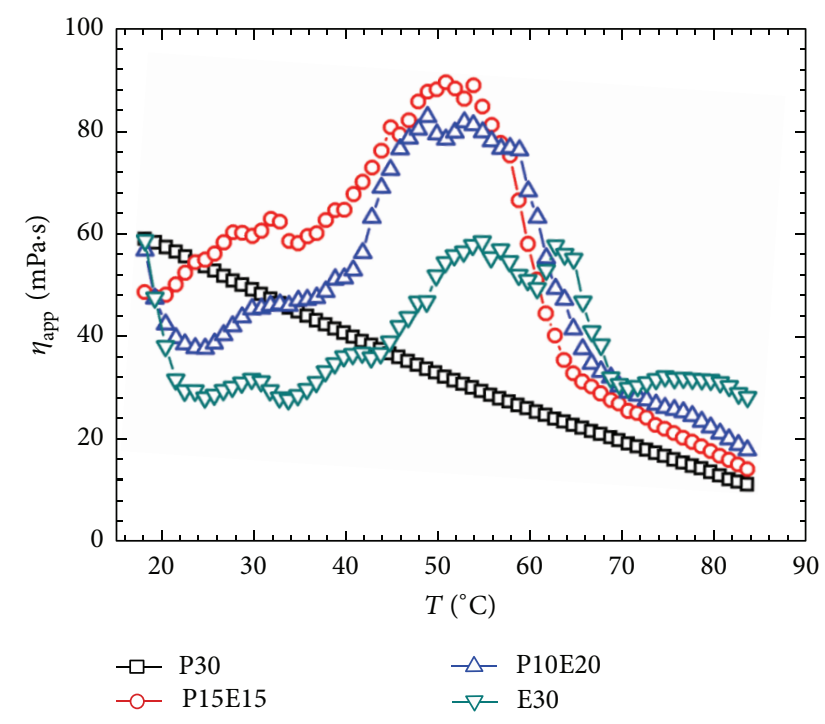

FIGURE 1: Effect of temperature on apparent viscosity of the samples $\left(\mathrm{TDS}=32,868 \mathrm{mg} / \mathrm{L},\left[\mathrm{Ca}^{2+}\right]+\left[\mathrm{Mg}^{2+}\right]=873 \mathrm{mg} / \mathrm{L}, \dot{\gamma}=7.34 \mathrm{~s}^{-1}\right.$, heating rate: $2^{\circ} \mathrm{C} / \mathrm{min}$ ).

to that of EDAB. But it is worth noting that the higher the polymer fraction, the higher the viscosity peak. It is also noteworthy that the hybrid samples show stronger thermothinning behaviors after the viscosity maximum compared to EDAB.

To pick out the optimized formulation used for oil displacement under the simulated oil reservoir condition, it is utmost important to compare all the hybrid samples, as well as the pure HPAM and EDAB solutions, at the target temperature. Summarized in Table 2 are the apparent viscosities of all the samples. It is quite surprising that there is no direct correlation between viscosity and the content of EDAB or HPAM. Although the viscosity of $0.3 \% \mathrm{EDAB}$ is $10 \mathrm{mPa} \cdot \mathrm{s}$ higher than that of $0.3 \%$ HPAM, the apparent viscosity of the $0.3 \%$ hybrid samples decreases first followed by continuous increase upon increasing the content of EDAB in the hybrid samples. Exceptionally, the sample P10E20 composed of $0.10 \%$ HPAM and $0.20 \%$ EDAB displays the apparent viscosity as high as $30.61 \mathrm{mPa} \cdot \mathrm{s}$, while P5E25 with $0.05 \%$ HPAM and $0.25 \%$ EDAB possesses viscosity of only $18.29 \mathrm{mPa} \cdot \mathrm{s}$, and P15E15 only has $11.25 \mathrm{mPa} \cdot \mathrm{s}$. In the following studies, the two hybrid samples, P15E15 and P10E20, will be employed for long-term thermostability and core flooding studies.

In order to distinguish whether HPAM undergo microstructural changes with the addition of EDAB, dynamic rheological experiments were performed at $85^{\circ} \mathrm{C}$ as well. Figure 2 shows the plots of storage modulus $\left(G^{\prime}\right)$ and loss

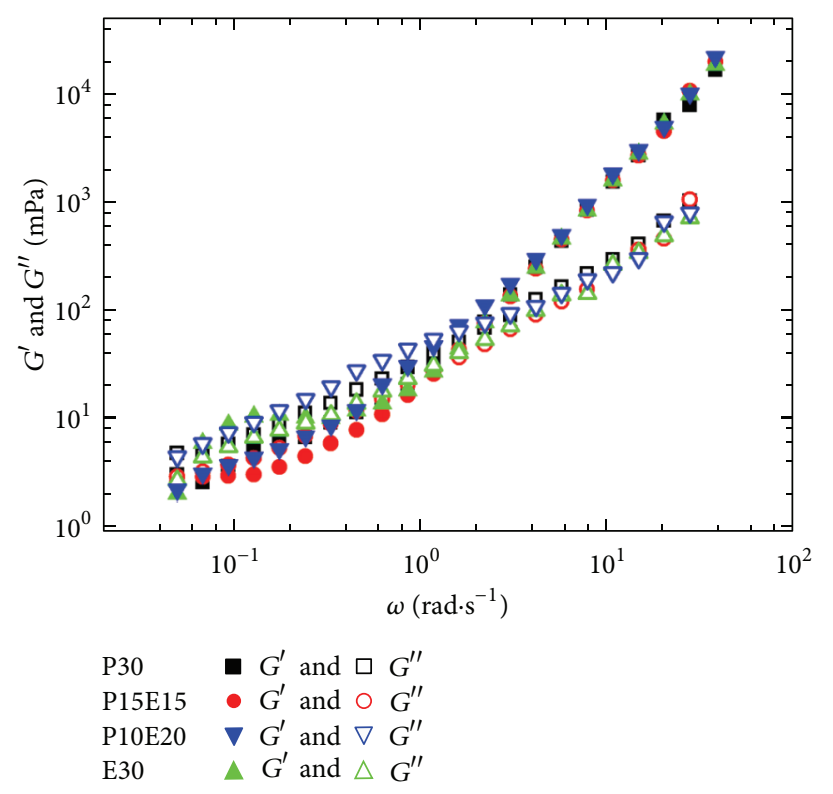

FIgUre 2: Storage modulus $\left(G^{\prime}\right)$ and loss modulus $\left(G^{\prime \prime}\right)$ plotted as a function of angular frequency $(\omega)$ for the samples (TDS = $\left.32,868 \mathrm{mg} / \mathrm{L},\left[\mathrm{Ca}^{2+}\right]+\left[\mathrm{Mg}^{2+}\right]=873 \mathrm{mg} / \mathrm{L}, T=85^{\circ} \mathrm{C}\right)$.

modulus $\left(G^{\prime \prime}\right)$ as a function of oscillatory shear frequency $(\omega)$ for the HPAM/EDAB hybrid samples. For the HPAM sample (P30), both moduli are strong functions of shear frequency over the entire frequency. When EDAB is added, the $G^{\prime}$ and $G^{\prime \prime}$ of the hybrid samples P15E15 and P10E20 remain nearly unchanged, especially at high frequencies. But it is worth noting that there are crossovers between $G^{\prime}$ and $G^{\prime \prime}$ for all the samples, indicative of the formation of network structures in the solution. These results suggest that HPAM does not undergo microstructural changes when EDAB is added and it still has the ability of increasing the oil recovery factor. Therefore, the hybrid samples have great potential to enhance oil recovery from high-temperature and highsalinity oil reservoirs because EDAB shows excellent heat and salinity tolerance.

3.2. Long-Term Thermal Stability. The remaining viscosity at high temperature represents a primary criterion for any chemicals to be used in hostile environment. For instance, the continuous aging of the displacing fluid is detrimental to tertiary oil recovery [25], particularly in high-temperature oil reservoirs. Therefore, high-temperature aging is crucial to EOR chemicals, and long-term thermal stability experiment of HPAM/EDAB hybrid samples is inescapably necessary.

Figure 3 shows the variation of $\eta_{\text {app }}$ as a function of aging time for the HPAM/EDAB hybrid samples and sole HPAM 
TABLE 3: Core parameters, displacement process, and recovery factors.

\begin{tabular}{lcccccccc}
\hline $\begin{array}{l}\text { Core } \\
\text { no. }\end{array}$ & $\begin{array}{c}\text { Permeability } \\
(\mathrm{mDarcy})\end{array}$ & $\begin{array}{c}\text { Pore volume } \\
\left(\mathrm{cm}^{3}\right)\end{array}$ & $\begin{array}{c}\text { Saturated oil } \\
\left(\mathrm{cm}^{3}\right)\end{array}$ & Slug & $\begin{array}{c}\text { Slug injected } \\
(\mathrm{PV})\end{array}$ & $\begin{array}{c}\text { Water } \\
\text { flooding } \\
\text { recovery }(\%)\end{array}$ & $\begin{array}{c}\text { Ultimate } \\
\text { recovery (\%) }\end{array}$ & $\begin{array}{c}\text { Enhanced oil } \\
\text { recovery }(\%)\end{array}$ \\
\hline 1 & 1059 & 53.4 & 43.0 & P30 & 0.3 & 55.10 & 70.95 & 15.85 \\
2 & 1480 & 50.6 & 42.0 & P15E15 & 0.3 & 60.85 & 71.05 & 10.20 \\
3 & 1496 & 50.0 & 41.0 & P10E20 & 0.3 & 45.10 & 52.20 & 7.10 \\
4 & 1494 & 49.0 & 41.0 & E30 & 0.3 & 35.95 & 37.85 & 1.90 \\
\hline
\end{tabular}

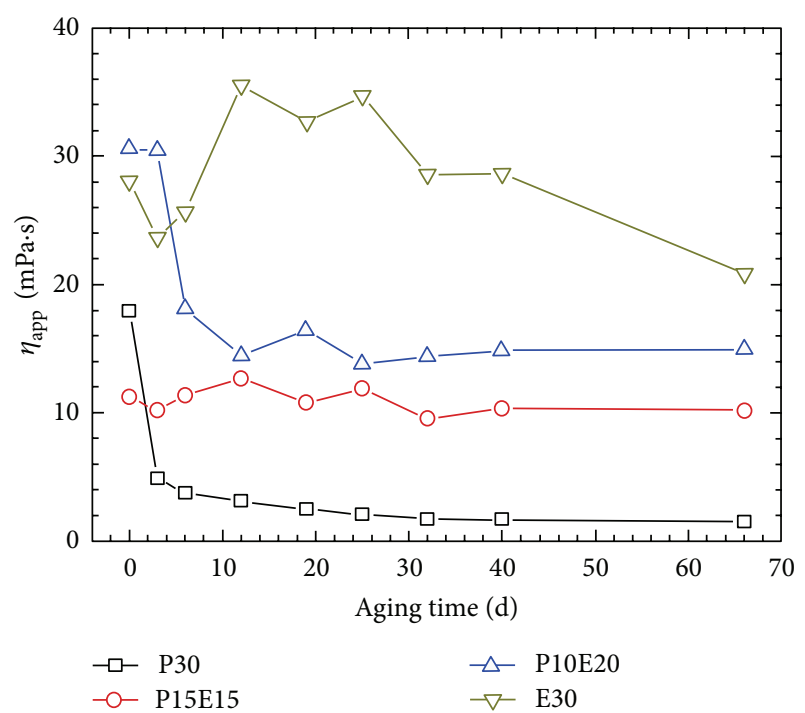

FIGURE 3: Long-term thermal stability of HPAM/EDAB hybrid samples in comparison with EDAB and HPAM (TDS $=32,868 \mathrm{mg} / \mathrm{L}$, $\left.\left[\mathrm{Ca}^{2+}\right]+\left[\mathrm{Mg}^{2+}\right]=873 \mathrm{mg} / \mathrm{L}, \dot{\gamma}=7.34 \mathrm{~s}^{-1}\right)$. Both the aging and measuring temperature is $85^{\circ} \mathrm{C}$.

or EDAB after aging at $85^{\circ} \mathrm{C}$. One can clearly find a sharp reduction in $\eta_{\text {app }}$ for HPAM (P30) after aging: the initial $\eta_{\text {app }}(0 \mathrm{~d})$ is $17.93 \mathrm{mPa} \cdot \mathrm{s}$, but is only $4.88 \mathrm{mPa} \cdot \mathrm{s}$ left for the same sample after 3 days of aging! There is also a sharp reduction in $\eta_{\text {app }}$ for P10E20 in 6 days: its $\eta_{\text {app }}$ decreases to $18.11 \mathrm{mPa} \cdot \mathrm{s}$, and $41 \%$ of loss in viscosity. However, after more than 25 days of aging, the $\eta_{\text {app }}$ of P10E20 begins to increase other than decrease. Unlike P30 and P10E20, the $\eta_{\text {app }}$ of P15E15 maintains a constant value regardless of aging time, showing improved long-term thermal stability over HPAM. Meanwhile, as shown in Figure 3, EDAB (E30) exhibits a much better thermal stability than HPAM after 66 days of aging. These results clearly demonstrate that the ultra-longchain zwitterionic surfactant EDAB possesses much better long-term thermal stability over HPAM, and the addition of EDAB into HPAM solutions will improve the thermal stability of HPAM solutions.

3.3. Oil Displacement Test. To our knowledge, there are no published data concerning chemical flooding using HPAM or EDAB under the simulated high temperature and salinity oil reservoir conditions. Although the HPAM/EDAB hybrid samples show promising potential for chemical EOR in hightemperature and high-salinity oil reservoirs, no core flooding test so far has been performed yet.

Plotted in Figure 4 are the recovery factors, water cut, and flooding pressure as a function of injected volume of the sample solutions under the simulated high-temperature and high-salinity oil reservoir environment. Table 3 shows core parameters, displacement process, and the results of these oil displacement tests. It was found that $15.85 \%$ oil recovery factor by HPAM (P30) flooding was obtained at these conditions (Figure 4(a)), whereas the oil recovery factor of EDAB (E30) was only $1.90 \%$ (Figure 4(b)). As shown in Figures 4(c) and 4(d), the oil recovery factor of P15E15 was $10.20 \%$ and the factor of P10E20 was 7.10\%; both of them are smaller than that of HPAM, but much higher than that of EADB. The main reason to get a higher oil recovery factor with the hybrid samples can be ascribed to strengthened micelles by the added HPAM long chains which are not as easy as that of micelles to be disrupted. It is worth emphasizing that the synergistic effect between HPAM and $\mathrm{EDAB}$ enables the hybrid sample to show an excellent longterm thermal stability and get a relatively high oil recovery factor. Under long-term propagation in the simulated hightemperature and high-salinity oil reservoirs, the apparent viscosity of the HPAM/EDAB hybrid sample is relatively stable, thus effectively improving water-to-oil mobility ratio to make more oil produced.

In spite of its poor long-term thermal stability, the $0.3 \%$ HPAM solution can still enhance oil recovery to a higher extent in the relative short period (10 hours) of oil displacement test. On the contrary, the oil recovery factor of $\mathrm{EDAB}$ is extremely low though it has much stronger thickening ability and much better long-term thermal stability under the simulated high-temperature and high-salinity oil reservoirs. The poor oil recovery efficiency may be attributed to the collapse of the micelles upon contacting oil, and the disassembled micelles by the shear and elongation force at the pore throats cannot be recovered when they reach the next throat. However, such a hypothesis should be further verified quantitatively in future studies.

The propagation of the different chemicals in porous media is schematically illustrated in Figure 5. In the flooding process, all the samples are subjected to shear and stretch in the pores of porous reservoir media. In this case, WLMs are destroyed and cannot form micelles in a short time (Figure 5(a)). However, HPAM molecular chains orient the flow direction and reform polymer coils after going through 


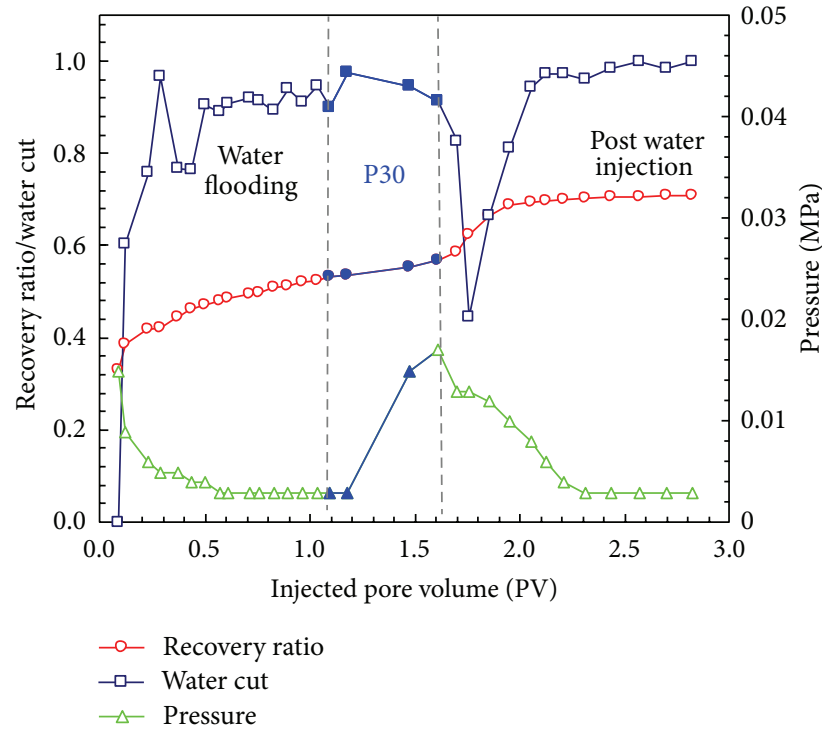

(a)

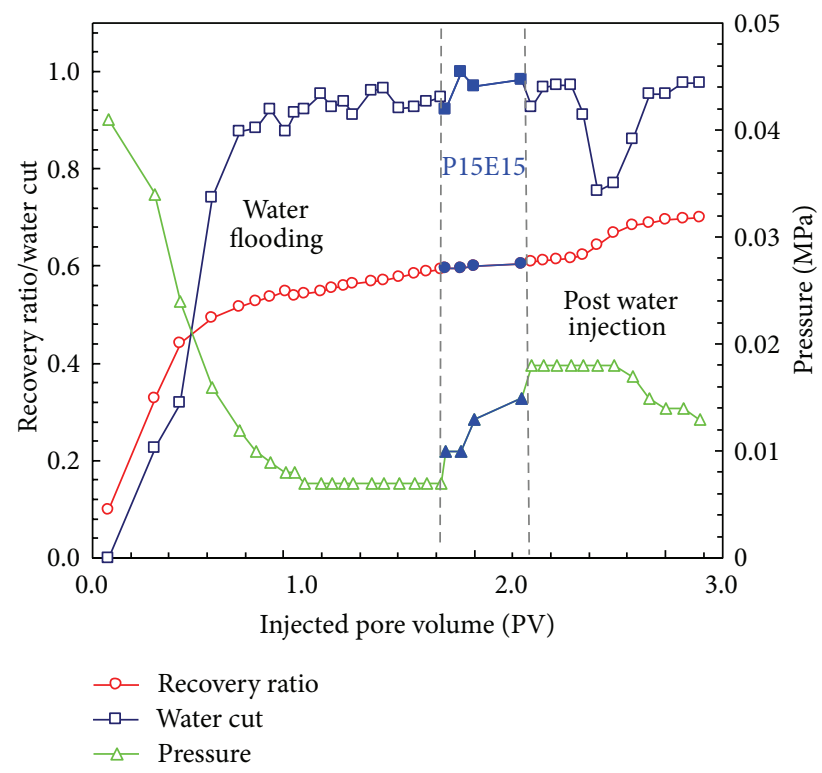

(c)

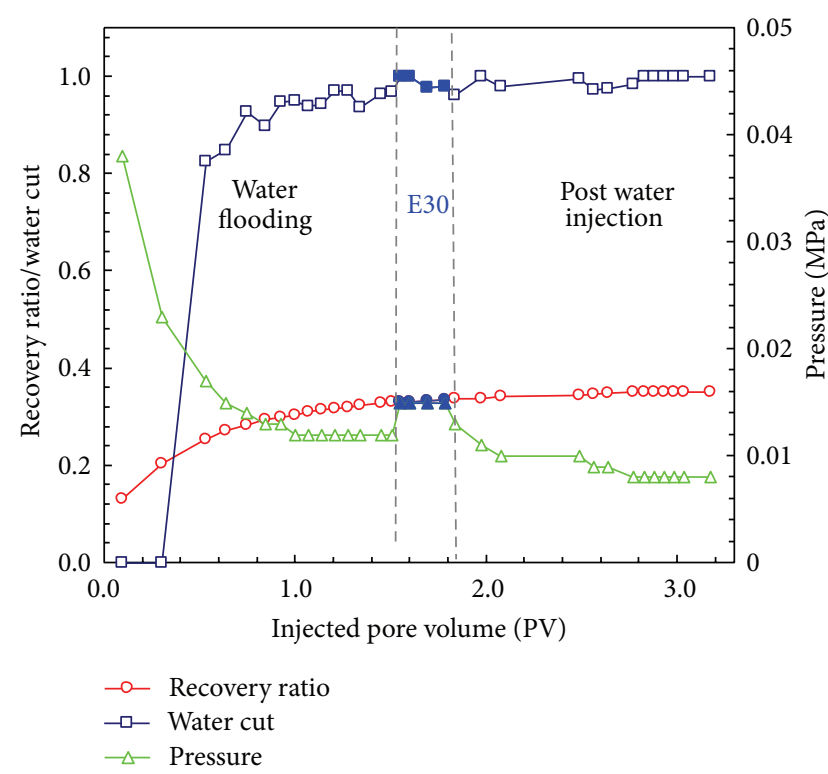

(b)

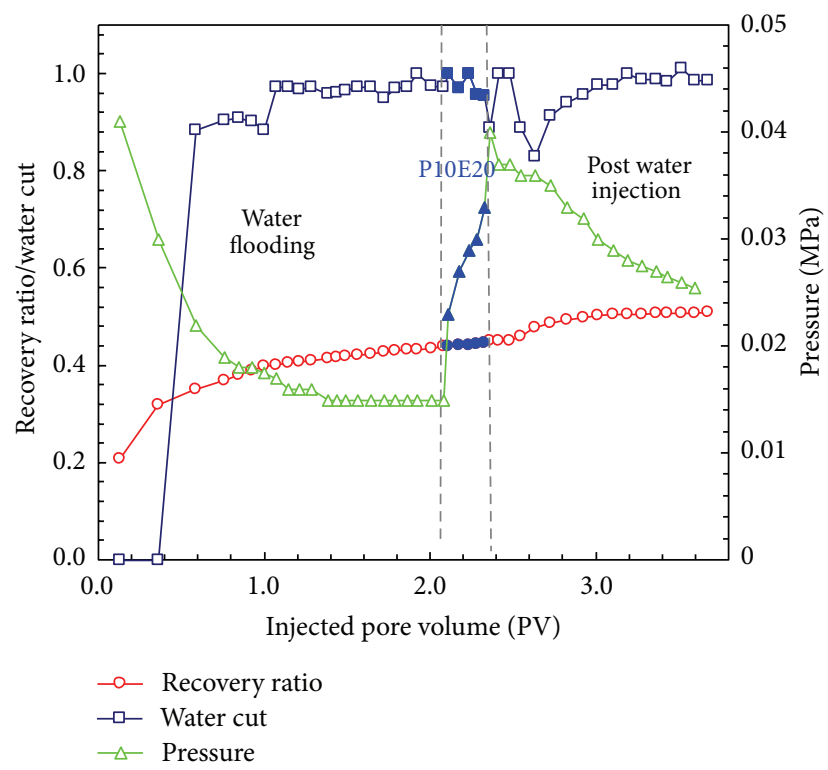

(d)

FIGURE 4: Recovery factor, water cut, and flooding pressure plotted as a function of injected volume of the samples: (a) P30, (b) E30, (c) $\mathrm{P} 15 \mathrm{E} 15$, and (d) P10E20 (TDS = 32,868 mg/L, $\left[\mathrm{Ca}^{2+}\right]+\left[\mathrm{Mg}^{2+}\right]=873 \mathrm{mg} / \mathrm{L}$; injected volume $=30 \% \mathrm{PV}$; injected rate $=0.23 \mathrm{~mL} / \mathrm{min}$ ).

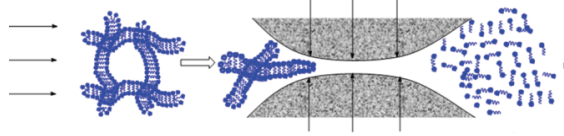

EDAB

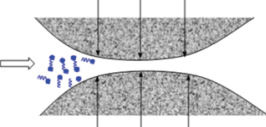

(a)

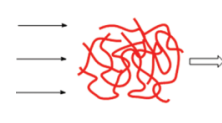

HPAM

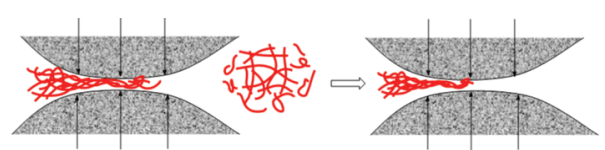

(b)
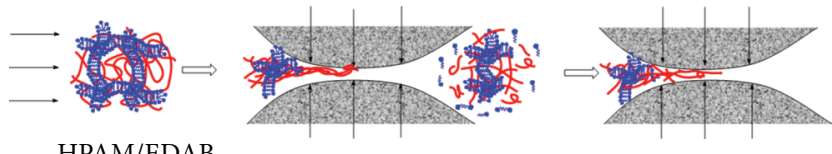

(c)

FIGURE 5: Schematic description of the chemical flooding processes for the samples: (a) EDAB, (b) HPAM, and (c) HPAM/EDAB hybrid. 
the porous media (Figure 5(b)). For the HPAM/EDAB hybrid samples, HPAM assists WLMs in going across the pores and prevents them from being destroyed (Figure 5(c)). Therefore, the oil recovery factor of the HPAM/EDAB hybrid sample is smaller than that of HPAM, but much higher than that of EADB.

\section{Conclusion Remarks}

The rheological behaviors of partially hydrolyzed polyacrylamide/amidobetaine surfactant hybrid and core flooding experiments under simulated high temperature and salinity oil reservoirs conditions were preliminarily examined. It was found that the HPAM/EDAB hybrid samples (P15E15 and P10E20) exhibited improved salt tolerance and long-term thermal stability. In addition, $10.20 \%$ and $7.10 \%$ of oil recovery factors were achieved from the HPAM/EDAB hybrid samples in the laboratory core flooding test. Along with their improved salt tolerance and long-term thermal stability, these hybrid samples show great potential to enhance oil recovery from hostile oil reservoir environment. However, it is necessary to further investigate the mechanism of the HPAM/EDAB hybrid and the optimum ratio between HPAM and $\mathrm{EDAB}$ for economic consideration.

\section{Acknowledgments}

The authors are grateful to the financial support from Shandong Provincial government through the "Taishan Scholar" project, Science and Technology Department of Sichuan Province (2012NZ0006, 2010JQ0029), as well as Natural Science Foundation of China (21173207, 21273223), and Chinese Academy of Sciences.

\section{References}

[1] S. Thomas, "Enhanced oil recovery-an overview," Oil \& Gas Science and Technology-Revenue d'IFP Energies Nouvelles, vol. 63, no. 1, pp. 9-19, 2008.

[2] K. S. Sorbie, Polymer-Improved Oil Recovery, Baca Raton, Fla, USA, 1991.

[3] J. C. Jung, K. Zhang, B. H. Chon, and H. J. Choi, "Rheology and polymer flooding characteristics of partially hydrolyzed polyacrylamide for enhanced heavy oil recovery," Journal of Applied Polymer Science, vol. 127, no. 6, pp. 4833-4839, 2013.

[4] Q. Chen, Y. Wang, Z. Lu, and Y. Feng, "Thermoviscosifying polymer used for enhanced oil recovery: rheological behaviors and core flooding test," Polymer Bulletin, vol. 70, no. 2, pp. 391401, 2013.

[5] Y. Wang, Z. Lu, Y. Han, Y. Feng, and C. Tang, "A novel thermoviscosifying water-soluble polymer for enhancing oil recovery from high-temperature and high-salinity oil reservoirs," Advanced Materials Research, vol. 306-307, pp. 654-657, 2011.

[6] A. Zaitoun and B. Poitie, "Limiting conditions for the use of hydrolysed polyacrylamides in brines containing divalent ions," in Proceedings of the SPE International Oilfield and Geothermal Chemistry Symposium, Paper SPE 11785, Denver, Colo, USA, June 1983.
[7] G. Chauveteau and K. S. Sorbie, "Mobility control by polymers," in Basic Concepts in Enhanced Oil Recovery Process, M. Bavière, Ed., vol. 33 of Critical Reports on Applied Chemistry, pp. 44-87, Elsevier, London, UK, 1991.

[8] A. Dupas, I. Hénaut, J. F. Argillier, and T. Aubry, "Mechanical degradation onset of polyethylene oxide used as a hydrosoluble model polymer for enhanced oil recovery," Oil \& Gas Science and Technology-Revenue d'IFP Energies Nouvelles, vol. 67, no. 6, pp. 931-940, 2012.

[9] C. Noïk, P. Delaplace, and G. Müller, "Physico-chemical characterics of polyacrylamide solutions after mechanical degradation through a porous medium," in Proceedings of the SPE International Symposium on Oilfield Chemistry, Paper SPE 28954, San Antonio, Tex, USA, February 1995.

[10] G. Dupuis, D. Rousseau, R. Tabary, J.-F. Argillier, and B. Grassl, "Hydrophobically modified sulfonated polyacrylamides for IOR: correlations between associative behavior and injectivity in the diluted regime," Oil \& Gas Science and TechnologyRevenue d'IFP Energies Nouvelles, vol. 67, no. 6, pp. 903-920, 2012.

[11] J. Yang, "Viscoelastic wormlike micelles and their applications," Current Opinion in Colloid \& Interface Science, vol. 7, no. 5-6, pp. 276-281, 2002.

[12] C. A. Dreiss, "Wormlike micelles: where do we stand? Recent developments, linear rheology and scattering techniques," Soft Matter, vol. 3, no. 8, pp. 956-970, 2007.

[13] Z. Chu, C. A. Dreiss, and Y. Feng, "Smart wormlike micelles," Chemical Society Review, vol. 42, pp. 7174-7203, 2013.

[14] Z. Chu, Y. Feng, X. Su, and Y. Han, "Wormlike micelles and solution properties of a C22-tailed amidosulfobetaine surfactant," Langmuir, vol. 26, no. 11, pp. 7783-7791, 2010.

[15] Z. Chu, Y. Feng, H. Sun et al., "Aging mechanism of unsaturated long-chain amidosulfobetaine worm fluids at high temperature," Soft Matter, vol. 7, no. 9, pp. 4485-4489, 2011.

[16] Z. Chu and Y. Feng, "Amidosulfobetaine surfactant gels with shear banding transitions," Soft Matter, vol. 6, no. 24, pp. 60656067, 2010.

[17] Z. Chu and Y. Feng, "A facile route towards the preparation of ultra-long-chain amidosulfobetaine surfactants," Synlett, no. 16, pp. 2655-2658, 2009.

[18] D. Feng, Y. Zhang, Q. Chen, J. Wang, B. Li, and Y. Feng, "Synthesis and surface activities of amidobetaine surfactants with ultra-long unsaturated hydrophobic chains," Journal of Surfactants and Detergents, vol. 15, no. 5, pp. 657-661, 2012.

[19] Z. Chu and Y. Feng, "Empirical correlations between Krafft temperature and tail length for amidosulfobetaine surfactants in the presence of inorganic salt," Langmuir, vol. 28, no. 2, pp. 1175-1181, 2012.

[20] Y. Han, Y. Feng, H. Sun, Z. Li, Y. Han, and H. Wang, "Wormlike micelles formed by sodium erucate in the presence of a tetraalkylammonium hydrotrope," The Journal of Physical Chemistry B, vol. 115, no. 21, pp. 6893-6902, 2011.

[21] Y. Han, Z. Chu, H. Sun, Z. Li, and Y. Feng, "'Green' anionic wormlike micelles induced by choline," RSC Advances, vol. 2, no. 8, pp. 3396-3402, 2012.

[22] J. Wang, J. Wang, B. Wang, S. Guo, and Y. Feng, "Synthesis and aqueous solution properties of polyoxyethylene surfactants with ultra-long unsaturated hydrophobic chains," Journal of Dispersion Science and Technology, vol. 34, no. 4, pp. 504-510, 2013. 
[23] H. Wang, X. Cao, J. Zhang, and A. Zhang, "Development and application of dilute surfactant-polymer flooding system for Shengli oilfield," Journal of Petroleum Science and Engineering, vol. 65, no. 1-2, pp. 45-50, 2009.

[24] H. K. Kotlar, O. Selle, and O. Torsaeter, "Enhanced oil recovery by COMB-flow: polymer floods revitalized," in Proceedings of the SPE International Symposium on Oilfield Chemistry, Paper SPE 106421, pp. 540-545, Houston, Tex, USA, February-March 2007.

[25] J. L. Cayias, M. E. Hayes, R. S. Schechter, and W. H. Wade, "Surfactant aging-possible detriment to the tertiary oil recovery," Journal of Petroleum Technology, vol. 28, pp. 985-988, 1976. 

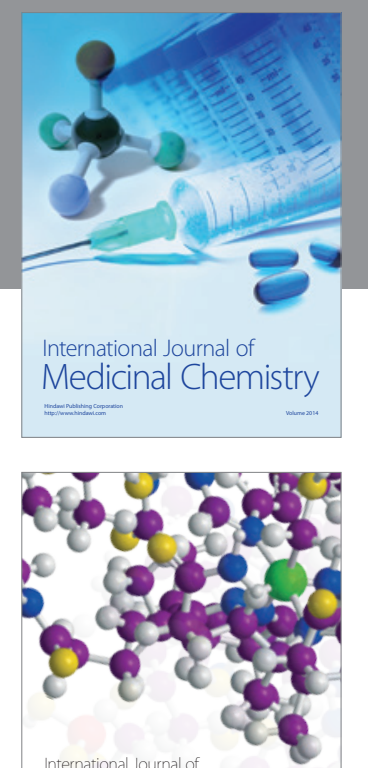

\section{Carbohydrate} Chemistry

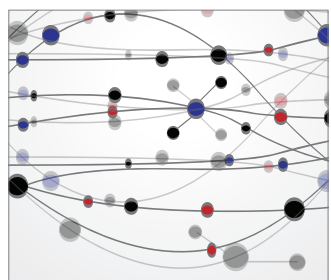

The Scientific World Journal
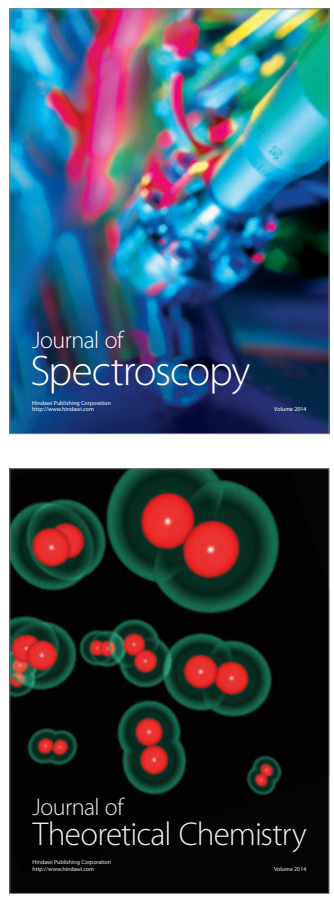
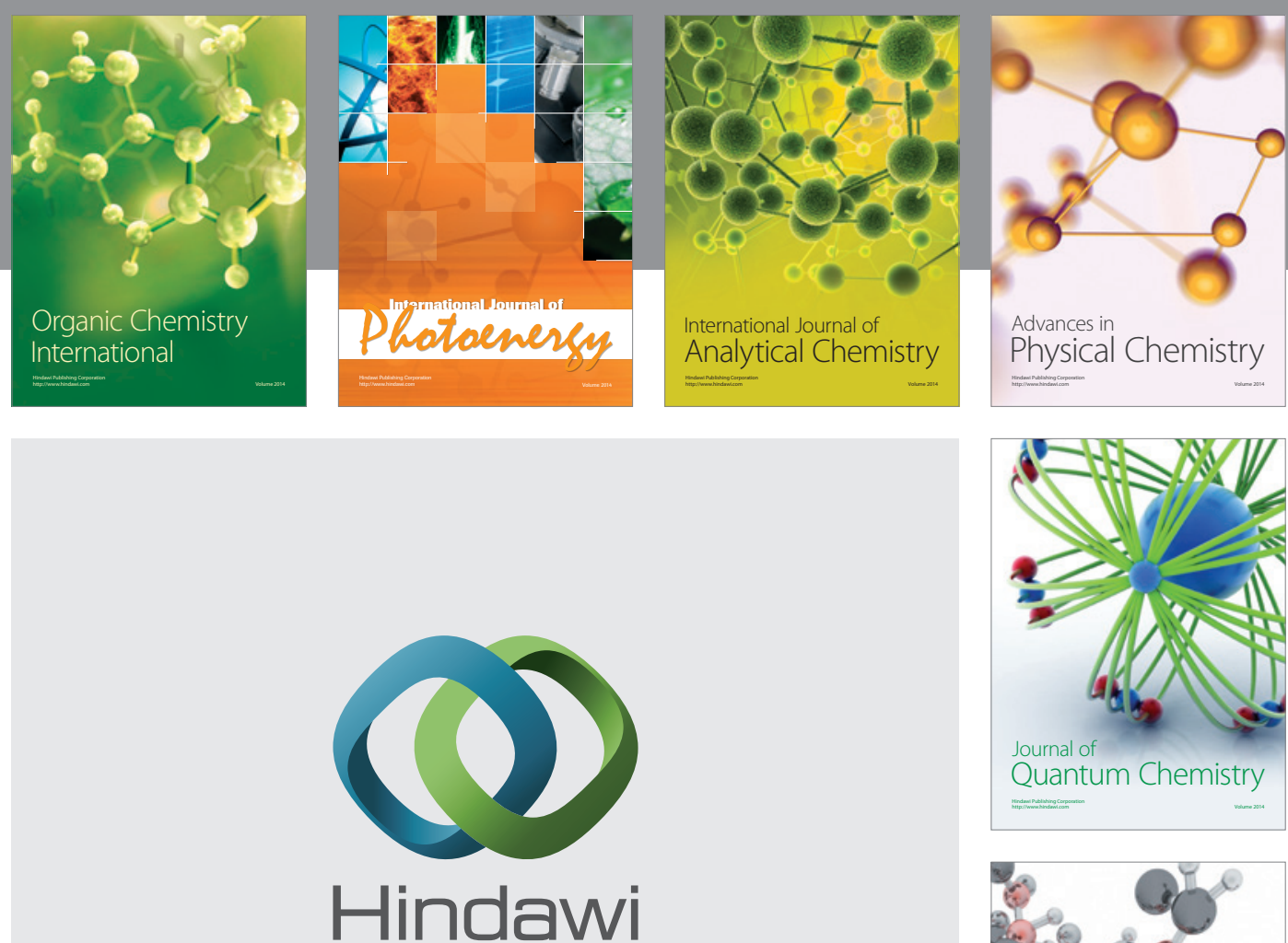

Submit your manuscripts at

http://www.hindawi.com

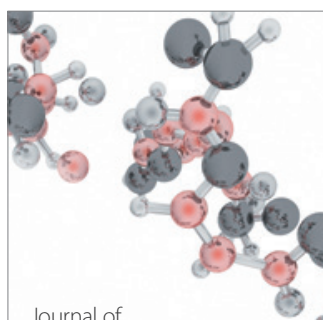

Analytical Methods

in Chemistry

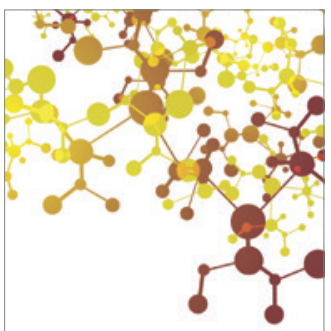

Journal of

Applied Chemistry

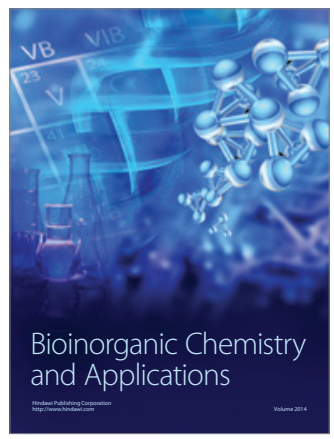

Inorganic Chemistry
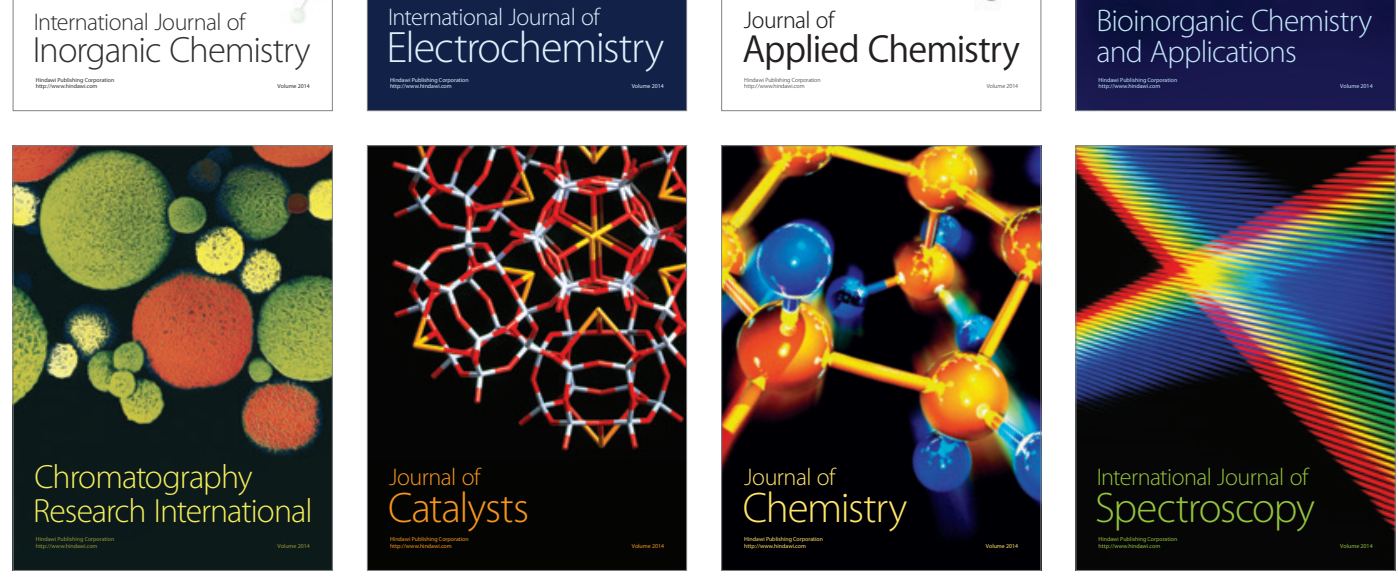